\title{
Influence of menstrual status on fluid replacement after exercise induced dehydration in healthy
} young women

\author{
Ronald J Maughan, Marion McArthur, Susan M Shirreffs
}

\begin{abstract}
Objective-To determine whether fluid replacement after exercise induced dehydration varies over the normal menstrual cycle.

Methods-Five subjects, with a regular menstrual cycle lasting $28(\mathrm{SEM} 2) \mathrm{d}$, were dehydrated by $1 \cdot 8(0 \cdot 1) \%$ of their preexercise mass by cycle exercise in the heat. Trials were undertaken $2 \mathrm{~d}$ before (trial $-2)$ and 5 and $19 \mathrm{~d}$ after the onset of menses (trials 6 and 20 respectively). After exercise, subjects ingested a fixed volume, equivalent to $150 \%$ of mass loss, of a commercially available sports drink over a 60 min period.
\end{abstract}

Results-Cumulative urine output [median(range)] over the $6 \mathrm{~h}$ following ingestion was the same on all trials: 714(469-750) $\mathrm{ml}$ on trial -2 ; 476(433-639) $\mathrm{ml}$ on trial 6; 534(195-852) $\mathrm{ml}$ on trial 20 . There was no menstrual cycle effect on urinary electrolyte $\left(\mathrm{Na}^{+}, \mathrm{K}^{+}, \mathrm{Cl}^{-}\right)$excretion or serum electrolyte $\left(\mathrm{Na}^{+}, \mathrm{K}^{+}, \mathrm{Cl}^{-}\right)$ concentrations. Plasma volume increased by $8-12 \%$ of the postexercise value following rehydration. The percentage of ingested fluid retained did not differ between trials at any time. Six hours after drink ingestion, net fluid balance was not different from the initial value on any of the trials.

Conclusions-Acute replacement of exercise induced fluid losses is not affected by the normal menstrual cycle.

(Br F Sports Med 1996;30:41-47)

Key terms: rehydration; fluid balance; menstrual cycle; exercise

Thermoregulation is known to be influenced by menstrual status, and fluid loss during exercise or heat stress may vary at different stages of the menstrual cycle in normal healthy young women. ${ }^{1}$ It is well established that several steroid hormones have an effect on fluid and electrolyte balance, and many women experience fluid retention in the luteal phase of the menstrual cycle: Fong and Kretsch ${ }^{2}$ reported differences in 24 hour urine output over the cycle in spite of a constant food and fluid intake. These observations raise questions as to whether there is an acute effect of hormonal status on fluid balance, and whether rehydration after exercise induced fluid loss is affected by the stages of the menstrual cycle in normal women.
The effects of providing beverages of different compositions on fluid homeostasis and exercise performance during exercise have been extensively studied, ${ }^{3-5}$ but there have been few investigations into the replacement of fluid losses after exercise. There is, however, growing evidence that, even though sweat is invariably hypotonic with respect to body fluids, replacement of volume losses is crucially dependent on restoration of electrolyte losses. ${ }^{6-8}$ The limited number of investigations on postexercise fluid replacement that have been carried out have all used males as subjects. This is at least in part a consequence of the possibility that the steroid hormones which are subject to cyclical variation in women may have an influence on fluid balance, and the wish of investigators to avoid this confounding factor. There are therefore two clear reasons to establish whether or not there is an acute effect of these hormones on fluid balance in the few hours after exercise induced sweat loss. Firstly, the question is in itself of inherent interest; there is a need to know whether these hormones play a physiological role in the maintenance of water and electrolyte balance. Secondly, there may be practical implications for those women engaged in sport or hard physical work in the heat if volume regulation is compromised

The present study was carried out to investigate whether the replacement of volume losses, as estimated by changes in blood and plasma volumes and in cumulative urine output, varies over the normal menstrual cycle. A group of women were investigated following sweat loss induced by exercise in the heat at different stages of their menstrual cycle. Fluid restoration in the postexercise period was monitored after replacement of the losses with a fixed volume of fluid of standardised composition.

\section{Methods}

Five healthy female volunteers completed this investigation and their physical characteristics [mean(SD)] were: age 23(2) years, height $164(4) \mathrm{cm}$, body mass $58 \cdot 4(4 \cdot 6) \mathrm{kg}$, maximum oxygen uptake $\left(\dot{\mathrm{VO}}_{2} \mathrm{max}\right) 42 \cdot 1(6 \cdot 8)$ $\mathrm{ml} \cdot \mathrm{kg}^{-1} \cdot \mathrm{min}^{-1}$, body mass index $22 \cdot 2(1 \cdot 1)$, and menstrual cycle length $28(4) \mathrm{d}$. The subjects were all free of any history of major medical problems; all took part occasionally in physical activity on a recreational basis, but none engaged in any form of systematic training at the time of the study. All subjects had a normal menstrual history, all reported regular cycles of 
constant length which varied in duration between individuals from 23-32 d, and none was taking any steroid contraceptives at the time of the study. The experimental procedures were approved by the joint ethics committee of the University of Aberdeen and Grampian Health Board and subjects were informed of the nature of the investigation before their written consent to participate was obtained.

Preliminary procedures undertaken by each subject before the start of the experiment were determination of $\mathrm{VO}_{2}$ max and a familiarisation trial. $\dot{\mathrm{VO}}_{2} \max$ was determined during an incremental exercise test on a cycle ergometer in order to determine the workload at which each individual would exercise in the heat. The familiarisation trial was identical to the experimental trials in all respects except that measurements were terminated and the subjects left the laboratory $2 \frac{1}{2}$ hours after the end of the exercise period.

All experimental trials began in the midafternoon, a minimum of $6 \mathrm{~h}$ after the last meal: ad libitum water intake was permitted until $3 \mathrm{~h}$ before the start of the experiment. No strenuous exercise was undertaken by the subjects before arrival at the laboratory on the days of the experiments, and they were requested to keep the composition of their last meal constant. No instructions were given to individuals as to what they could or could not consume in this meal, with the exception of abstaining from alcohol.

Each subject undertook three experimental trials representing different stages of the menstrual cycle and a fourth trial, repeated at the same stage as the first trial, to serve as a check on the reproducibility of the responses. These corresponded to $2 \mathrm{~d}$ before the onset of menses (trial -2), $5 \mathrm{~d}$ after the onset of menses (trial 6) and $19 \mathrm{~d}$ after the onset of menses (trial 20). Therefore, trial 6 took place in the mid-follicular phase at the end of menses, trial 20 took place in the mid-luteal phase, and trial -2 in the late luteal phase, shortly before the onset of menses (day 1 of the cycle). These trials took place on the same day of the week, which allowed subjects to standardise their activities in the days preceding each trial and also allowed recovery between trials. Three of the subjects performed trial -2 as their first trial and two performed trial 6 first. The fourth trial was undertaken to ascertain the reproducibility of the responses and to ensure that the study included a complete menstrual cycle; it was a repeat of either trial -2 or trial 6 , whichever was the first undertaken by the subject.

On arrival at the laboratory, subjects were seated in a room maintained at a moderate temperature (approximately $20^{\circ} \mathrm{C}$ ) for $15 \mathrm{~min}$, after which time a $5 \mathrm{ml}$ blood sample was taken from a superficial antecubital vein. The subject was then requested to give a urine sample by emptying her bladder as completely as possible, and the entire volume was collected. The dehydration procedure started after measurement of nude body mass. Subjects were first immersed to the neck in a tank of water maintained at a temperature of $42^{\circ} \mathrm{C}$ for
$10 \mathrm{~min}$ to initiate the sweating response: this was followed by intermittent cycle ergometer exercise in a warm room $\left(33-34^{\circ} \mathrm{C}\right.$, relative humidity approximately $60 \%$ ). Pilot studies established that the duration of exercise necessary to induce a fixed level of dehydration was substantially reduced by the water immersion procedure as rectal temperature was raised by approximately $1-1.5^{\circ} \mathrm{C}$ by the process. The exercise was performed for periods of $10 \mathrm{~min}$, interspersed by $5 \mathrm{~min}$ rest periods during which time nude body mass measurements were made in order to monitor the degree of mass loss. Exercise was at a moderate intensity, calculated to be approximately $60 \%$ of $\mathrm{VO}_{2}$ max for each subject. After a maximum of six exercise sessions, or sooner if the body mass loss was approaching $2 \%$ (the remaining mass was lost with continued perspiration after exercise before the final mass measurement was made), the subject had a shower before measurement of the final body mass; 15 min was allowed for this procedure before the subject had to return to her seat for a further $15 \mathrm{~min}$ in preparation for a second blood sample collection. During this time a $21 \mathrm{G}$ butterfly cannula was introduced into a superficial forearm vein. This cannula remained in place for the remainder of the study and allowed blood samples to be obtained without interruption of blood flow: the cannula was kept patent between samples by flushing with heparinised saline after the collection of each sample.

After collection of the second urine sample, the rehydration process began and the fluid (a commercially available sports drink: $6.4 \%$ carbohydrate, $25 \mathrm{mmol} \cdot$ litre $^{-1} \mathrm{Na}^{+}, \quad 3.5$ mmol-litre ${ }^{-1} \mathrm{~K}^{+}$, and $12 \mathrm{mmol} \cdot$ litre $^{-1} \mathrm{Cl}^{-}$) was given in a volume (in $\mathrm{ml}$ ) equal to 1.5 times the mass loss (in $\mathrm{g}$ ) resulting from the dehydration process. Body mass loss due to substrate oxidation was estimated to be no more than about $90 \mathrm{~g}$, and was ignored for the purposes of this study; all mass loss was therefore assumed to be due to fluid loss. The total volume to be ingested was divided into four equal parts, each of which was consumed over a 15 min period. For effective rehydration, we have previously shown that the volume of fluid consumed must be greater than that lost during dehydration to surmount the ongoing obligatory urine output. ${ }^{910}$

The subjects remained seated during the final $15 \mathrm{~min}$ of the rehydration period and a third blood sample was collected after this time. Immediately following blood sampling, a urine sample was collected as before. Further blood and urine samples were collected 1, 2, 4 , and $6 \mathrm{~h}$ after the end of the rehydration period and in each case the subject remained seated for a minimum of $15 \mathrm{~min}$ before collection of each blood sample. All blood was collected without stasis. For each urine sample the subject emptied her bladder as completely as possible and the entire volume was collected.

\section{ANALYTICAL PROCEDURES}

Part $(2.5 \mathrm{ml})$ of each blood sample was immediately mixed with anticoagulant 
(EDTA, $1.5 \mathrm{mg} \cdot \mathrm{ml}^{-1}$ ) and used for measurement of packed cell volume (by microcentrifugation) in triplicate and haemoglobin concentration (by the cyanmethaemoglobin method) in duplicate. Changes in blood and plasma volume were calculated according to the method of Dill and Costill ${ }^{11}$ using these packed cell volume and haemoglobin measurements and relating all changes to the sample collected $30 \mathrm{~min}$ after the end of exercise. The remainder of each blood sample was allowed to clot and the serum separated by centrifugation. Measurements were made of serum osmolality by freezing point depression (Gonotec Osmomat 030 cryoscopic osmometer), sodium and potassium concentrations by flame photometry (Corning clinical flame photometer 410C), and chloride concentration by coulometric titration (Jenway chloride meter).

The total volume of each urine sample was measured and an aliquot retained for estimation of osmolality and electrolyte concentrations using the same methods as for serum analysis.

\section{STATISTICAL ANALYSIS}

Data were analysed by two factor analysis of variance (ANOVA) for repeated measures. After testing for normality of distribution, data were subjected to one way ANOVA followed by the Tukey test (normally distributed data) or the Kruskal-Wallis and Mann-Whitney tests (data not normally distributed) where appropriate. Differences were accepted as significant when a $P$ value of less than 0.05 was obtained. Data in text, tables, and figures are expressed as mean(SEM) or median (range) of values as appropriate.

\section{Results}

For each subject there was a consistency of duration of the menstrual cycle: all subjects correctly predicted their onset of menstruation and the final trial undertaken occurred at the same time of the cycle relative to the first trial undertaken.

Pre-exercise body mass did not differ at the different menstrual cycle stages $(P=0.999)$. The mean body mass loss by the dehydration process was $1 \cdot 8(0 \cdot 1) \%$ of the pre-exercise nude body mass over all trials and there was no difference in the extent of the dehydration between the three different stages $(P=0.483)$. The total exercise time was the same on all trials [54(3) $\mathrm{min}]$ and the estimated mean rate of sweating during the dehydration period was $12 \cdot 8(1 \cdot 5) \mathrm{g} \cdot \mathrm{min}^{-1}$ on trial $-2,11 \cdot 6(1 \cdot 7) \mathrm{g} \cdot \mathrm{min}^{-1}$ on tral 6 , and $10 \cdot 7(2 \cdot 4) \mathrm{g} \cdot \mathrm{min}^{-1}$ on trial 20 . There was no difference in the sweat rate at the different menstrual cycle stages $(P=0.737)$ and no change from week to week over the duration of the experiment $(P=0.941)$.

The rehydration fluid was given in a volume equivalent to $150 \%$ of the mass loss resulting from the dehydration process. The extent of body mass loss for each trial was $1.9 \%$ on trial $-2,1.8 \%$ on trial 6 , and $1.6 \%$ on trial 20 . Therefore, the volumes of fluid ingested on each trial were $1662(87) \mathrm{ml}$ on trial -2 , $1550(77) \mathrm{ml}$ on trial 6 , and $1392(108) \mathrm{ml}$ on trial 20. However, due to the small intraindividual variations between trials in the pre-exercise mass and in the mass loss, there were no differences in the extent of dehydration or drink volumes consumed on each of the trials.

URINE VOLUME AND COMPOSITION

The cumulative urine output following rehydration was calculated for $6 \mathrm{~h}$ after the end of the rehydration period. There was no difference in the total volume excreted over this period at the different menstrual cycle stages $(P=0 \cdot 164$, table 1$)$. On all trials, peak urine production occurred during the hour following the end of the rehydration period and amounted to $230(23) \mathrm{ml}$ over all trials.

Urine osmolality did not differ between trials at any time point $(P=0.794)$. The osmolality was inversely related to the volume of urine excreted $(\mathrm{r}=-0.539, \mathrm{P}<0.001 ; \mathrm{n}=105)$; osmolality ranged from $950 \mathrm{mmol} \cdot \mathrm{kg}^{-1}$ when urine volume was small, to $86 \mathrm{mmol} \cdot \mathrm{kg}^{-1}$ with large urine volumes.

There was no difference between trials in the total amount (mmol) of electrolytes excreted in the urine following rehydration: $\mathrm{Na}^{+}$: trial -2 , $20 \cdot 4(16 \cdot 1-30 \cdot 5)$; trial $6,14 \cdot 8(12 \cdot 6-35 \cdot 2)$; trial $20,21 \cdot 5(10 \cdot 5-29 \cdot 9), \mathrm{P}=0.428 ; \mathrm{K}^{+}$: trial $-2,17 \cdot 8(14 \cdot 1-23 \cdot 5)$; trial $6,16 \cdot 3(7 \cdot 7-22 \cdot 7)$; trial $20,15 \cdot 0(11 \cdot 1-21 \cdot 8), \mathrm{P}=0.433 ; \mathrm{Cl}^{-}$: trial $-2,15 \cdot 4(10 \cdot 1-21 \cdot 3)$; trial $6,12 \cdot 1(8 \cdot 2-23 \cdot 7)$; trial $20,14 \cdot 4(7 \cdot 9-21 \cdot 8), P=0.930$.

WHOLE BÓDY FLUID BALANCE

From the body mass loss, the volume of fluid ingested, and the volume of urine excreted, net fluid balance was calculated. At the beginning of the study, subjects were considered to be euhydrated (that is, they were in exact fluid balance). On losing fluid either as urine or sweat they become more negatively hydrated, and on gaining fluid by drinking they become more positively hydrated. The percentage of ingested fluid retained (that is, that fraction not lost in urine) was also calculated. There was no difference in the state of net fluid balance between trials $(P=0.564)$ over the $6 \mathrm{~h}$ following the end of the rehydration period (fig 1), and consequently the percentage of the rehydration fluid which was retained at the end of each trial was not different $(P=0.633$, table 2). At the end of the study, $6 \mathrm{~h}$ after the end of the rehydration period, subjects were euhydrated on all trials.

\section{BLOOD AND PLASMA CHANGES}

The first blood sample after dehydration was collected $30 \mathrm{~min}$ after the end of exercise. Between the pre- and postdehydration samples, there was no change in blood $(P=0.818)$ or plasma $(P=0.517)$ volume on any trial. Some restoration of these volumes probably occurred between the end of exercise and the collection of the first postexercise sample $^{7}$. With rehydration, both blood and plasma volumes increased above their starting levels (figs 2 and 3). The plasma volume $1 \mathrm{~h}$ after the end of the rehydration period was significantly increased above both the pre- and 
Table 1 Cumulative urine output $(\mathrm{ml})$ to each time point on each of the experimental trials. Values are median (range). No significant differences were observed between trials at any time

\begin{tabular}{lccc}
\hline $\begin{array}{l}\text { Time after } \\
\text { rehydration }\end{array}$ & Trial -2 & Trial 6 & Trial 20 \\
\hline $0 \mathrm{~h}$ & $17(14-25)$ & $12(11-29)$ & $18(18-26)$ \\
$1 \mathrm{~h}$ & $302(253-374)$ & $258(79-328)$ & $238(42-326)$ \\
$2 \mathrm{~h}$ & $553(345-615)$ & $385(297-499)$ & $391(90-526)$ \\
$4 \mathrm{~h}$ & $673(433-720)$ & $456(373-575)$ & $461(150-824)$ \\
$6 \mathrm{~h}$ & $714(469-750)$ & $476(433-639)$ & $534(195-852)$ \\
\hline
\end{tabular}

postdehydration levels on all trials. This increased volume was approximately $8-12 \%$ greater than initial levels and was maintained for the remainder of the study period.

Serum osmolality had a tendency to increase with dehydration (table 3 ) but did not differ significantly from the pre-exercise value throughout the investigation $(P>0.05)$. The osmolality recorded at the first sampling point following dehydration was greater than those recorded 2, 4, and $6 \mathrm{~h}$ after the end of the rehydration period.

There was no effect of menstrual status on serum electrolyte concentration at any time. Over all trials the serum sodium, potassium, and chloride concentrations before and after exercise were $140(136-143)$ and 146 (144-148) $\mathrm{mmol} \cdot$ litre $^{-1}, 4 \cdot 3(3 \cdot 3-5 \cdot 1)$ and $4 \cdot 2$ (3.5-5.3) mmol-litre ${ }^{-1}$, and $100(97-102)$ and 102 (97-107) $\mathrm{mmol} \cdot$ litre $^{-1}$ respectively. The serum sodium concentration following dehydration was greater than the concentrations recorded $1,2,4$, and $6 \mathrm{~h}$ after the end of the rehydration period on all trials, as well as being

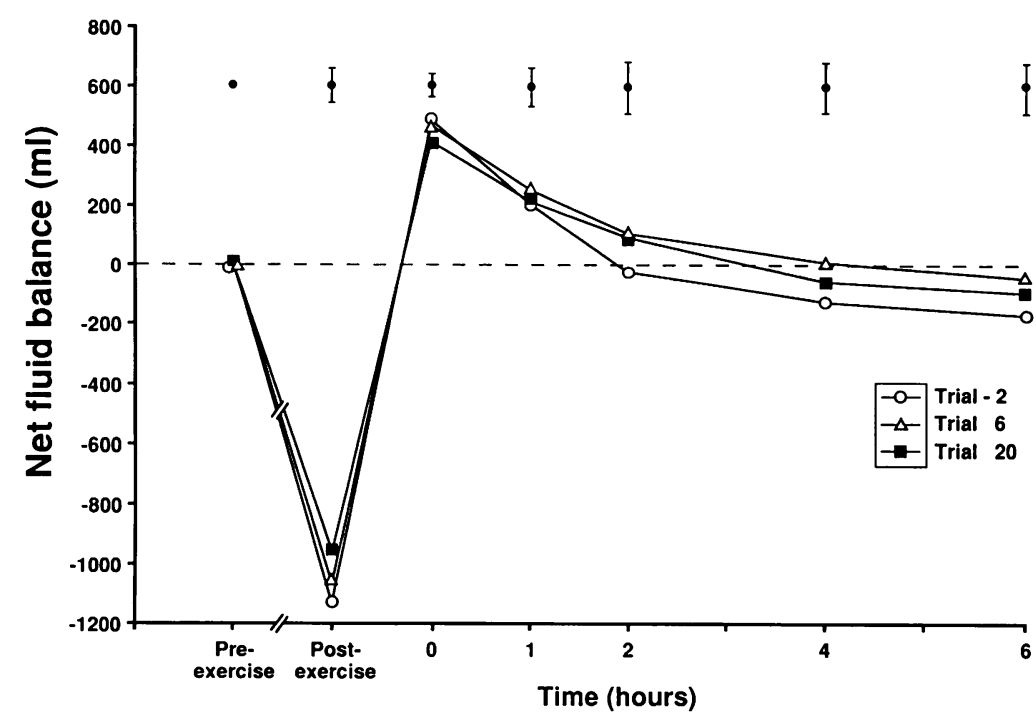

Fig 1 Net fluid balance calculated from the volumes of sweat loss, fluid ingested, and urine output over the course of the experiment. The pre-exercise urine sample is not included in these calculations. The group SEM of the values for all trials at each time point is represented at that time point

Table 2 Percentage of ingested drink retained at each time point following rehydration, calculated from the volume consumed and the cumulative urine output. Values are mean(SEM). No significant differences were observed between trials at any time

\begin{tabular}{llll}
\hline & Trial -2 & \multicolumn{1}{l}{ Trial 6 } & \multicolumn{1}{c}{ Trial 20 } \\
\hline Volume of fluid ingested (ml) & $1662(87)$ & $1550(77)$ & $1392(108)$ \\
Time after rehydration & & & \\
$0 \mathrm{~h}$ & $98 \cdot 8(0 \cdot 1)$ & $98 \cdot 9(0 \cdot 2)$ & $98 \cdot 6(0 \cdot 2)$ \\
$1 \mathrm{~h}$ & $81 \cdot 1(1 \cdot 8)$ & $82 \cdot 2(2 \cdot 4)$ & $84 \cdot 3(4 \cdot 6)$ \\
$2 \mathrm{~h}$ & $66 \cdot 6(4 \cdot 2)$ & $74 \cdot 4(3 \cdot 5)$ & $74 \cdot 3(6 \cdot 8)$ \\
$4 \mathrm{~h}$ & $60 \cdot 4(4 \cdot 8)$ & $68 \cdot 3(2 \cdot 7)$ & $65 \cdot 7(8 \cdot 1)$ \\
$6 \mathrm{~h}$ & $57 \cdot 8(4 \cdot 6)$ & $65 \cdot 4(2 \cdot 8)$ & $62 \cdot 8(8 \cdot 0)$ \\
\hline
\end{tabular}

greater than the predehydration value (table 4 ). The concentrations recorded $1,2,4$, and $6 \mathrm{~h}$ after the end of the rehydration period did not differ from the pre-exercise values. Serum potassium and chloride concentrations remained essentially the same as the pre-exercise values throughout the study.

CONSISTENCY OF RESPONSES

Each subject underwent four experimental trials: trial -2 , trial 6 , trial 20 , and a repeat of one of these. Trial -2 was repeated by three individuals and trial 6 was repeated by the other two. By studying each individual twice under identical conditions, the consistency of responses could be ascertained and the ability of each of the subjects to correctly predict their cycle length demonstrated.

With duplicate trials, there was no difference in the extent of the dehydration $(P=0.405)$ and hence volume of fluid consumed. The urine excreted at each time point $(P=0.572)$, cumulative urine output $(P=0.310)$, quantity of electrolytes excreted $\left(\mathrm{Na}^{+}, \mathrm{P}=0 \cdot 100 ; \mathrm{K}^{+}\right.$, $\mathrm{P}=0.699 ; \mathrm{Cl}^{-}, \mathrm{P}=0.410$ ), net fluid balance $(P=0.906)$, and percentage of fluid retained $(P=0.550)$ showed no differences between duplicate trials. Additionally, none of the blood indices showed any variation between these trials (change in blood volume, $P=0.527$; change in plasma volume, $P=0.359$; serum osmolality, $P=0.220$; serum $\mathrm{Na}^{+}, \mathrm{P}=0.292$; serum $\mathrm{K}^{+}, \mathrm{P}=0.465$; serum $\mathrm{Cl}^{-}, \mathrm{P}=0 \cdot 163$ ).

\section{Discussion}

The primary finding from our study is that the acute replacement of volume losses incurred by exercise induced dehydration is not affected by the normal menstrual cycle. This suggests that women are not disadvantaged when rapid and complete restoration of exercise induced sweat loss is required. These results may also have important consequences for future work concerning post-exercise rehydration: as no differences were found between different menstrual cycle stages in any of the measured variables, it would be feasible to include females together with males in studies of this nature. It is, of course, recognised that the subject number in the present study is small, and that the subjects were selected on the basis of the regularity of their cycle. It also became apparent, although this was not a selection criterion, that none of these individuals experienced premenstrual water retention. Many athletes, and especially those engaged in intensive endurance training, experience disturbances of hormonal status leading to amenorrhoea or oligomenorrhoea, and the responses of these individuals may well be different, although there is at present no good reason to suppose that this is the case.

A level of $2 \%$ hypohydration was aimed for in the present study because this has been shown in previous investigations, where the effects of solutions of different composition were evaluated, to be an adequate level from which to observe differences in rehydration effectiveness. ${ }^{691012}$ There are perhaps also practical reasons for using such a modest level 


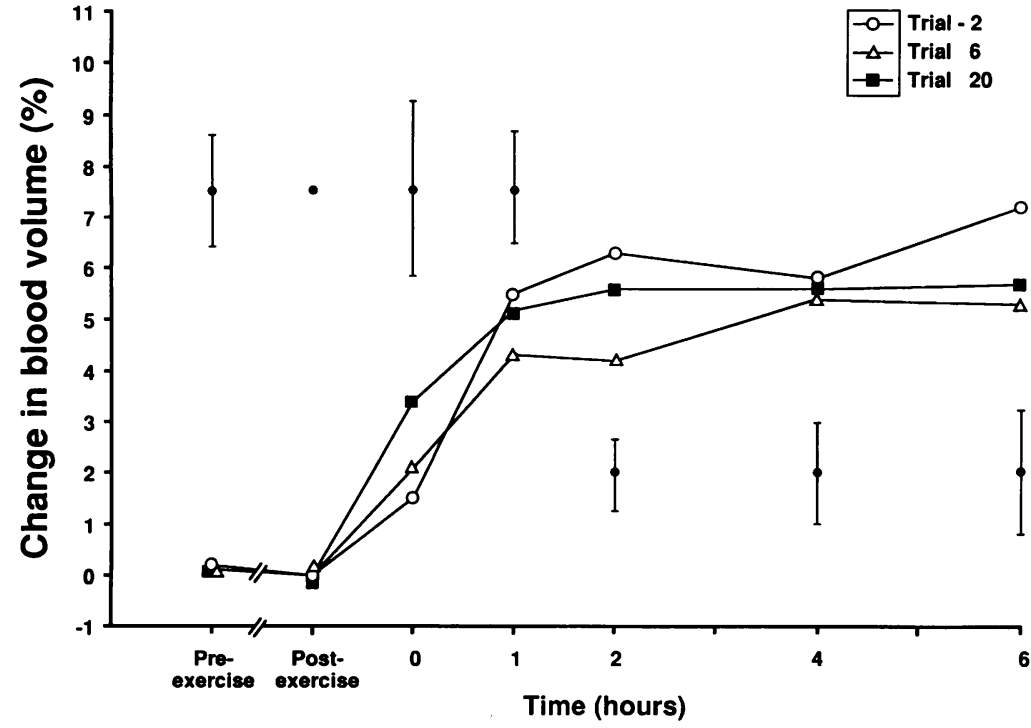

Fig 2 Percent change in blood volume calculated from packed cell volume and haemoglobin measurements. Changes are calculated relative to the blood sample taken 30 min after the end of exercise. The group SEM of the values for all trials at each time point is represented at that time point

of hypohydration, because greater fluid losses are seldom encountered by normal healthy individuals except in extreme exercise.

The inclusion in the present study of two trials on corresponding days of consecutive menstrual cycles (the first and last trials undertaken by each subject) provided verification that subjects could accurately

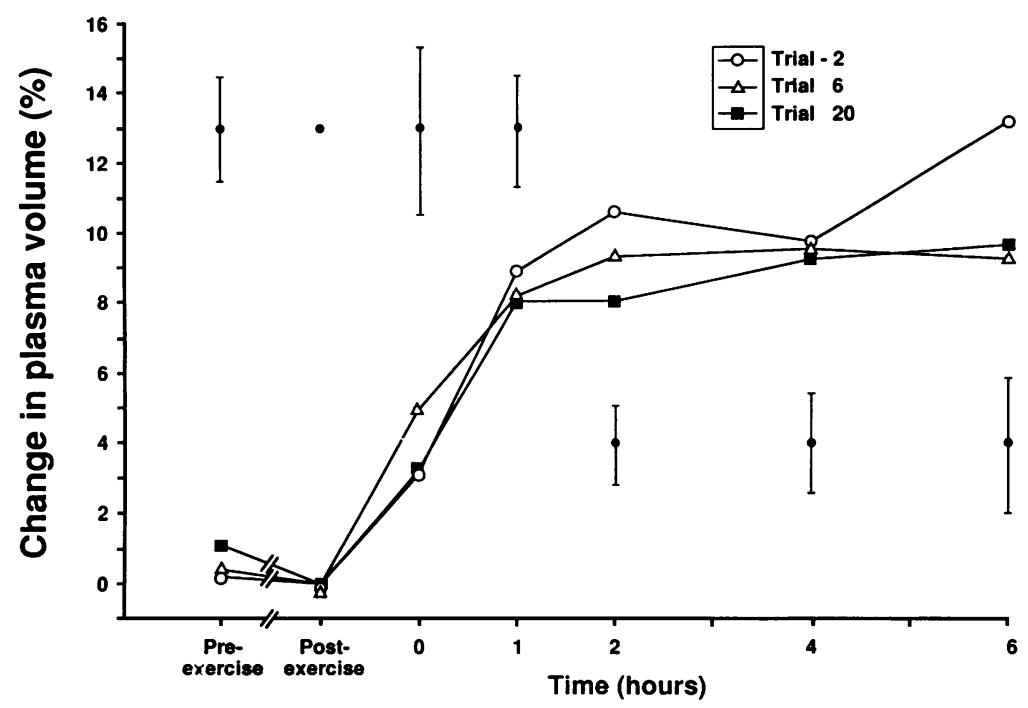

Fig 3 Percent change in plasma volume calculated from packed cell volume and haemoglobin measurements. Changes are calculated relative to the blood sample taken 30 min after the end of exercise. The group SEM of the values for all trials at each time point is represented at that time point

Table 3 Serum osmolality $\left(\mathrm{mmol} \cdot \mathrm{kg}^{-1}\right)$ at each time point on each of the experimental trials. Values are mean (SEM)

\begin{tabular}{llll}
\hline $\begin{array}{l}\text { Time after } \\
\text { rehydration }\end{array}$ & Trial -2 & Trial 6 & Trial 20 \\
\hline Pre-exercise & $283(1)$ & $290(2)$ & $284(3)$ \\
Postexercise & $288(1)$ & $295(2)$ & $288(1)$ \\
0 h & $288(2)$ & $293(3)$ & $288(2)$ \\
1 h & $282(3)$ & $286(1)^{\star}$ & $283(1)$ \\
h h & $280(2)^{\star}$ & $283(1)^{\star}$ & $280(2)^{\star}$ \\
4h & $278(2)^{\star}$ & $284(1)^{\star}$ & $279(2)^{\star}$ \\
6 h & $279(2)^{\star}$ & $285(2)^{\star}$ & $279(2)^{\star}$ \\
\hline
\end{tabular}

*Significantly less than the postexercise value for the corresponding trial $(P<0.05)$. predict their cycle length and also enabled post-hoc tests to be performed to establish the statistical power of the study. The mean difference in net water balance at the end of the experimental period between the two corresponding trials was $18(37) \mathrm{ml}$. With this degree of variance for these five subjects, a difference at different stages of the menstrual cycle of $170 \mathrm{ml}$ net fluid balance six hours after the end of the rehydration period would have a $100 \%$ chance of being detected, and a difference of $130 \mathrm{ml}$ (the difference between trials -2 and 6 [fig 1]) a 94\% chance of being detected. Previous studies have shown that the addition of sodium or potassium at a concentration of $25 \mathrm{mmol} \cdot \mathrm{litre}^{-1}$ to plain water results in an increase in net fluid retention of more than $300 \mathrm{ml}^{6}{ }^{12}$ This seems to give a clear indication that the subject number employed in the present study, although small, is adequate to detect a physiologically meaningful difference in fluid balance, and lends credence to the conclusion that postexercise rehydration is not acutely affected by menstrual status in untrained healthy eumenorrheic young women.

Although the difference was not statistically significant, there was a tendency for a larger volume of fluid to be ingested on trial -2 as a result of a slightly larger mass loss during dehydration on this trial. This is probably responsible for the tendency for a greater cumulative urinary output during this trial and consequent a lower fraction retained, as the additional volume ingested was not retained. Previous observations as to the relationship between the volume of fluid consumed and its effectiveness in promoting rehydration suggest that when the sodium content of the ingested beverage is low $\left(23 \mathrm{mmol} \cdot \operatorname{litre}^{-1}\right)$, a large urinary excretion is stimulated when a large volume of fluid is consumed. ${ }^{9}$ With a high sodium content $\left(61 \mathrm{mmol} \cdot \mathrm{litre}^{-1}\right)$, however, a larger proportion of the fluid is retained, resulting in a better net fluid balance. ${ }^{10}$ The drink used in the present study had a sodium content of $25 \mathrm{mmol} \cdot$ litre $^{-1}$. Relative to the sodium concentration of sweat, ${ }^{13}$ which varies in the range of $20-80 \mathrm{mmol} \cdot \mathrm{litre}^{-1}$, this drink therefore has a relatively low sodium content. Intake of fluid with a low electrolyte content adds water in excess of solute to the blood and has the effect of increasing blood volume and lowering osmolality. These two effects suppress the release of vasopressin ${ }^{14}$ and hence urine output is stimulated. This diuresis, which occurs in spite of a net water deficit, can be reduced by ingesting a rehydration beverage which will add substantial quantities of sodium as well as water to the blood. ${ }^{12}$ The fraction of the ingested fluid retained in this study $[62 \cdot 0(3 \cdot 1) \%]$ was similar to that observed in a previous study $[64 \cdot 8(6 \cdot 3) \%]$ where the subjects consumed the same volume relative to their weight loss of a beverage with a similar sodium content $\left(23 \mathrm{mmol} \cdot\right.$ litre $\left.^{-1} \mathrm{Na}^{+}\right) .{ }^{9}$ By increasing the sodium concentration of the beverage or by adding potassium, ${ }^{6}$ a greater proportion of the ingested fluid is retained. This effect of the composition of the ingested 
Table 4 Serum sodium concentration ( $\mathrm{mmol} \cdot \mathrm{litr}^{-1}$ ) at each time point on each of the experimental trials. Values are median (range)

\begin{tabular}{llll}
\hline $\begin{array}{l}\text { Time after } \\
\text { rehydration }\end{array}$ & Trial -2 & Trial 6 & Trial 20 \\
\hline Pre-exercise & $141(136-141)^{\star}$ & $139(138-143)^{\star}$ & $140(137-143)^{\star}$ \\
Postexercise & $147(145-157)$ & $147(144-149)$ & $145(144-149)$ \\
$0 \mathrm{~h}$ & $143(140-147)$ & $142(139-146)$ & $143(141-145)$ \\
$1 \mathrm{~h}$ & $143(138-144)^{\star}$ & $140(139-143)^{\star}$ & $142(140-143)^{\star}$ \\
$2 \mathrm{~h}$ & $140(138-143)^{\star}$ & $140(138-140)^{\star}$ & $140(139-141)^{\star}$ \\
$4 \mathrm{~h}$ & $140(137-140)^{\star}$ & $139(137-140)^{\star}$ & $139(138-139)^{\star}$ \\
$6 \mathrm{~h}$ & $140(137-142)^{\star}$ & $138(136-141)^{\star}$ & $138(137-140)^{\star}$ \\
\hline
\end{tabular}

fluid on fractional retention is far greater than any tendency for week to week variations recorded across the menstrual cycle in this study.

Some of the water lost as sweat during the dehydration phase of the experiment must have come from the vascular space, so the apparent absence of a reduction in the blood or plasma volumes with dehydration is surprising. However, during exercise and in the subsequent recovery period there is a redistribution of water among the body fluid compartments. During exercise, altered hydrostatic and osmotic forces result in movement of water from the vascular space to the interstitial spaces of the exercising muscles. ${ }^{15}$ The first postexercise blood sample was not obtained until 30 minutes after the end of exercise, and some restoration of blood volume will have occurred in this period. ${ }^{7}$ In similar studies with male subjects, however, we have generally found a reduction in blood and plasma volumes when they were dehydrated to the same extent as the females in this study..$^{9} 10$ In these experiments, the male subjects generally require less time to dehydrate to the same extent and they also exercise at a greater absolute work load. Plasma volume tends to show a rapid decrease in the early stages of exercise, with the extent of the decrease proportional to the exercise intensity, and some recovery of plasma volume generally occurs in the later stages of prolonged exercise. Therefore, possible explanations for the different blood and plasma volume profiles with dehydration are that either distribution of water losses among the different body water compartments is such that a smaller fraction is derived from the vascular space in females, or that the longer exercise time in the female subjects allowed a greater recovery of plasma volume from other body water spaces before drink ingestion. Additionally, females have a greater fat to lean body mass ratio than men, and the body water content, expressed as a fraction of body mass, is therefore normally less in women than in men. A $2 \%$ reduction in body mass consequently represents a greater relative water deficit for women than it does for men.

The cyclical neuroendocrine variations that occur over the normal menstrual cycle have a number of effects in women. ${ }^{1}$ Water retention and associated body mass increases in relation to the luteal phase of the menstrual cycle are widely reported. ${ }^{16} 17$ The retention of water and accompanying electrolytes may be in part due to the effects of oestrogens, ${ }^{18}$ but it is also possible that increased vasopressin secretion at this time ${ }^{19}$ contributes to the fluid retention. An increased storage of muscle glycogen in the mid-luteal phase even in individuals consuming their normal $\operatorname{diet}^{20}$ has been reported to occur, and this will have the effect of retaining more water: every gram of glycogen is stored with $2-4 \mathrm{~g}$ of water. ${ }^{21}{ }^{22} \mathrm{In}$ the present study body mass was recorded only on experimental days and showed no evidence of differences at different menstrual cycle stages, suggesting that there was no luteal fluid retention in these subjects.

Core temperature is increased in the luteal phase of the menstrual cycle. ${ }^{23} 24$ Several studies have reported that the onset of sweating occurs at a higher core temperature during this phase of the menstrual cycle compared to the follicular phase in women with a normal menstrual cycle. ${ }^{25-30}$ Conversely, Sargent and Weinman ${ }^{31}$ reported no differences throughout the menstrual cycle in eccrine sweat gland activity (in response to sweating provoked either by sudorific drug administered intracutaneous acetyl- $\beta$-methylcholine - or by heat exposure) in terms of the latent period of reflex sweating, sweat rate, the number of active sweat glands and the gland flow. No measurements of body temperature were made on individuals in the present study, but the sweat rate during exercise did not differ at the different menstrual stages investigated. The time to the onset of sweat secretion was not monitored, as all subjects began to sweat during the 10 minute warm water immersion before exercise. Circadian fluctuations in body temperature, ${ }^{29}$ with mean core temperature being approximately $0.4^{\circ} \mathrm{C}$ lower in the early morning than in the mid-afternoon, require that for trials to be comparable, and to allow menstrual cycle stage comparisons rather than diurnal fluctuations, all trials should begin at approximately the same time of day: in the present study all trials began in the midafternoon. Trials took place on the same day of the week and individuals had followed the same activity pattern on the preceding day and day of the experiment.

In conclusion, the results of our investigation suggest that acute restoration of fluid balance after exercise induced hypohydration is unaffected by the normal menstrual cycle in healthy untrained eumenorrheic young women.

One of the authors (SMS) was supported by a Student Research Award from the Gatorade Sports Science Institute.

1 Stephenson LA, Kolka MA. Thermoregulation in women. (Holloszy JO, ed.) Exerc Sports Sci Rev 1993;21:231-62. Fong AKH, Kretsch MJ. Changes in dietary intake, urinary Fong AKen, Kretsch nitrogen, and urinary volume

3 Coyle EF, Coggan AR. Effectiveness of carbohydrate feeding in delaying fatigue during prolonged exercise.

4 Lamb DR, Brodowicz GR. Optimal use of fluids of varying formulations to minimize exercise-induced disturbances
formand in homeostasis. Sports Med 1986;3:247-74.

5 Maughan RJ. Fluid and electrolyte loss and replacement in exercise. $\mathcal{F}$ Sports Sci 1991;9(special issue):117-42.

6 Maughan RJ, Owen JH, Shirreffs SM, Leiper JB. Postexercise rehydration in man: effects of electrolyte addition to ingested fluids. Eur $\mathcal{F}$ Appl Physiol 1994;69:209-15.

7 Nose H, Mack GW, Shi X, Nadel ER. Shift in body fluid compartments after dehydration in humans. $\mathcal{F}$ Appl Physiol 1988;65:318-24. 
8 Nose H, Mack GW, Shi X, Nadel ER. Involvement of sodium retention hormones during rehydration in humans. F Appl Physiol 1988;65:332-6.

9 Maughan RJ, Taylor AJ, Shirreffs SM, Leiper JB. Postexercise rehydration in man: effects of volume consumed exercise rehydration in man: effects of vol
[abstr]. F Physiol (Lond) 1994;475P:29P.

10 Maughan RJ, Shirreffs SM. Effect of intake volume on rehydration after exercise in man [abstr]. Med Sci Sports Exerc 1994;26:S205.

11 Dill DB, Costill DL. Calculation of percentage changes in volumes of blood, plasma, and red cells in dehydration. f Appl Physiol 1974;37:247-8.

12 Maughan RJ, Leiper JB. Sodium intake and post-exercise rehydration in man. Eur $\mathcal{F}$ Appl Physiol 1995;71:311-9.

13 Maughan RJ. Fluid and electrolyte loss and replacement in exercise. f Sport Sci 1991;9:117-42.

14 Weitzman RE, Farnsworth L, MacPhee R, Wang C-C, Bennett $\mathrm{CM}$. Effect of opposing osmolar and volume factors on plasma arginine vasopressin in man. Miner Electrolyte Metab 1978;1:43-7.

15 Harrison MH. Effects of thermal stress and exercise on blood volume in humans. Physiol Rev 1985;65:149-209.

16 Greene $\mathrm{R}$, Dalton $\mathrm{K}$. The premenstrual syndrome. $B M F$ 1953;i:1007-14.

17 Sweeney JS. Menstrual edema. $7 A M A$ 1934;103:234-6.

18 Briggs JP, Sawaya BE, Schnermann J. Disorders of salt balance. In: Kokko JP, Tannen RL, eds. Fluids and balance. In: Kokko JP, Tannen RL, eds. Fluids
electrolytes. Philadelphia: W. B. Saunders, 1990:106.

19 Forsling ML, Akerlund MA, Stromberg P. Variations in plasma concentrations of vasopressin during the menstrual cycle. F Endocrinol 1982;89:263-6.

20 Hackney AC. Effects of the menstrual cycle on resting muscle glycogen content. Horm Metab Res 1990;22:647.
21 McBride JJ, Guest MM, Scott EL. The storage of the major liver components; emphasizing the relationship of glycogen to water in the liver and the hydration of glycogen to water in the liver and
glycogen. $\mathcal{F}$ Biol Chem 1941;139:943-52.

22 Olsson KE, Saltin B. Variation in total body water with muscle glycogen changes in man. Acta Physiol Scand muscle glycoge

23 Kleitman N, Ramsaroop A. Periodicity in body temperature and heart rate. Endocrinology 1948;43:1-20.

24 Rothchild I, Barnes AC. The effects of dosage, and of estrogen, androgen or salicylate administration on the degree of body temperature elevation induced by progesterone. Endocrinology 1952;50:485-96.

25 Bittel J, Henane R. Comparisons of thermal exchanges in men and women under neutral and hot conditions. $f$ Physiol (Lond) 1975;250:475-89.

26 Haslag SWM, Herztman AB. Temperature regulation in young women. 7 Appl Physiol 1965;20:1283-8.

27 Hessemer V, Bruck K. Influence of menstrual cycle on shivering, skin blood flow, and sweating responses measured at night. $\mathcal{F}$ Appl Physiol 1985;59:1902-10.

28 Hessemer V, Bruck $\mathrm{K}$. Influence of menstrual cycle on thermoregulatory, metabolic, and heart rate responses to exercise at night. $f$ Appl Physiol 1985;59:1911-7.

29 Kolka MA, Stephenson LA. Control of sweating during the human menstrual cycle. Eur $f$ Appl Physiol 1989;58: 890-5.

30 Stephenson LA, Kolka MA. Menstrual cycle phase and time of day alter the reference signal controlling arm blood flow and sweating. Am F Physiol 1985;249:R186-234.

31 Sargent F, Weinman KP. Eccrine sweat gland activity during the menstrual cycle. $\mathcal{F}$ Appl Physiol 1966;21: 1685-7. 